University of Nebraska - Lincoln DigitalCommons@University of Nebraska - Lincoln

To Improve the Academy

Professional and Organizational Development

Network in Higher Education

1983

\title{
The Relationship of Institutional Planning and Institutional Research to Faculty Development
}

Carol A. Paul

Follow this and additional works at: http://digitalcommons.unl.edu/podimproveacad

Part of the Higher Education Administration Commons

Paul, Carol A., "The Relationship of Institutional Planning and Institutional Research to Faculty Development" (1983). To Improve the Academy. 39.

http://digitalcommons.unl.edu/podimproveacad/39

This Article is brought to you for free and open access by the Professional and Organizational Development Network in Higher Education at DigitalCommons@University of Nebraska - Lincoln. It has been accepted for inclusion in To Improve the Academy by an authorized administrator of DigitalCommons@University of Nebraska - Lincoln. 


\section{The Relationship of Institutional Planning and Institutional Research to Faculty Development}

\section{Carol A. Paul}

Fairleigh Dickinson University

Institutional Research (IR), institutional academic planning (IAP), and faculty development (FD) are interactive. They can all work together to advance institutional development. This model expresses the interaction:

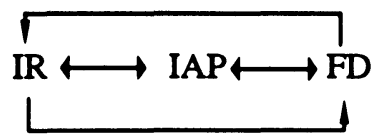

It is possible to understand this interactive relationship better by viewing the historical development of institutional research, institutional academic planning and faculty development and then providing examples of how they interact in institutions today and describing what factors influence effective interaction.

\section{Institutional Research}

Up through the 1960s, most data collected at colleges and universities stayed isolated in the individual offices which had done the collecting. For example, admissions offices maintained data on the number of applicants versus enrollments, the geographic origin of 
students, their SAT scores, etc. Meanwhile, offices of the Vice-President for Academic Affairs, or its equivalent, maintained data on the number of tenured versus non-tenured faculty, ranks of faculty, highest degree, etc., while the business office generated data on cost-revenue ratios and average class size. Generally, no particular office or officer was in charge of maintaining operational data; rather, several different offices or officers invested various amounts of time and commitment to maintaining institutional data. One of the major functions of these data was for self-studies required by regional accrediting agencies (Kell, 1980, p. 11).

The 1970s brought a new era, mainly as a result of external pressures such as affirmative action, increased federal and state financial aid, budgetary constraints, demand for accountability by legislators, and increased demands for a variety of data from specialized accrediting agencies. At the same time, computers became available. They could store data much more efficiently than could office files. This shifted responsibility for operational data from individual offices to a central office. The result in many institutions was an Office of Institutional Research and an officer known as a Director of Institutional Research.

The permutations on this model were many. In smaller institutions, the Director of Research wore more than one hat and thus might concurrently serve as Director of Development or Director of the Computer Center. Also, a clear distinction developed between institutional operational data and institutional research. When most institutional research offices were created, they initially were involved in developing systems that collected and stored institutional operational data. The advent of institutional research came later as the pressures mounted to evaluate programs and to develop additional student services.

Today, in most institutions, an office of institutional research maintains operational data for the entire institution while concurrently accepting institutional research projects. Such an office is a legitimate and important support to institutional planning and development. 


\section{Academic Planning}

There are two basic ways of reviewing academic programs, vertically or horizontally. When a program is viewed vertically, it is developed in its department and moves through the review process of an institution without serious consideration of its impact on other programs, such as the core curriculum and student services. When a program is reviewed horizontally, it moves from its department through the review process with serious consideration given to its impact and interaction with existing programs and services. For example, if a B.S. in Computer Science is to be developed and implemented, its impact on the core curriculum, counseling services, and staffing patterns would have to be assessed. If financial allocations are fixed, except for inflationary increases, then some other program would have to be reduced in size and its financial resources reallocated in order for computer science to be implemented.

Up through the 1960s, academic planning was more often than not influenced by internal strengths and wishes. Institutional growth in programs and building was the norm and funding continued to exist so these programs/projects could be developed and implemented through vertical review system. By the 1970 s, with increased competition for funding and the beginning of a serious decline in the 18-25 year-old cohort normally enrolled in higher education, planners began to turn to strategic planning which matches environmental opportunities and constraints with internal strengths, weaknesses, and personal values (Shirley, 1979, pp. 4-7).

Strategic planning requires that new programs be implemented and existing programs be expanded or contracted on the basis of criteria that assess programmatic need, quality, and cost (Shirley, 1978, pp. 479-482). This involves a horizontal review of programs where impact on other programs is considered and reallocation of resources is common practice.

It is probably important to note that both institutional research and institutional planning, as conceived today, have been greatly affected by external pressures and constraints. Within this framework, institutions of higher education can no longer consider only their internal circumstances when considering their futures. 


\section{Examples of Relationship of Institutional Planning and Research to Faculty Development}

Now let us move on to the interactive effect of institutional planning, institutional research and faculty development by giving some examples. Table 1 (see the end of the paper) provides an outline for an educational plan. Step III and V require the development of baseline enrollment projections and planning projections, both of which normally are developed by the office of institutional research. Step VII identifies staffing for a plan as one of its more complex facets. In the case of the cited example, retention, it is quite possible that new roles, such as counseling or teaching remedial courses, would fall to existing faculty and staff. In this instance, the responsibility for setting up a training program would fall to the faculty development office.

A second example is demonstrated through a planning exercise that reviews programs horizontally. Table 2 (at the end of the paper) provides a simple analysis for three programs. As the data indicate, the computer science program is expected to grow while the nursing program will stabilize and the mathematics program will decline. Both mathematics and computer science are central to the institution's mission and have a locational advantage as the sole programs in the region. Likewise, their cost revenue ratio is very good. On the other hand, nursing is not central to the institution's mission and has no geographic advantage because it is one of three in the region. From a planning point of view, nursing should be terminated as a program, mathematics should be decreased in size, and computer science should be expanded.

In order to undertake this type of planning analysis, it is necessary to have enrollment projections and information on quality, need, and cost. The institutional research office would be expected to generate these data and information.

If the institution in this example is similar to many in this decade, the nursing and mathematics faculty probably are tenured. In this instance, it would be advantageous to have a faculty development program that would be capable of working with these tenured faculty to set up a retraining program for them in the field of computer science. 


\section{Factors That Influence Effective Interaction}

The organizational placement of these three offices will affect their interaction. If they all report to the same administrator, there is a greater likelihood that their interaction will be smooth and effective.

Size of the institution is also a factor. In a large institution, it is more difficult for these offices to report to the same administrator, while concurrently it is more difficult for broad based institutional planning or faculty development to be widely understood and accepted. In a small institution, there is a greater chance that the person responsible for any one of these areas is also responsible for some other area. This dual responsibility can funnel energy and time away from institutional research, planning, or faculty development, thereby diminishing the potential impact of any one of them.

For a variety of reasons, any one of these areas - institutional research, institutional planning, or faculty development - may have a low status within the institution or be performed with little effectiveness. If that happens, greater tension is created among them and interactive relationships are less functional.

Sometimes the function and role of each of these areas has not been clearly delineated and defined. When this happens, different constituencies do not have a common understanding of the responsibilities of these areas. For example, if academic planning is indeed based upon a horizontal review of programs, all programs should be considered together, and this should be understood by all constituencies within the institution.

When one is considering serious interaction among institutional research, planning and faculty development, it is a good idea to start with a discussion of what each is and is not. Thereafter, the interactive functioning can be based on reality. 


\section{References}

Kells, H.R. Self-Study Processes. Washington, D.C.: American Council on Education, 1980.

Shirley, Robert C. and J. Frederick Volkwein. "Establishing Academic Program Priorities." Journal of Higher Education: 1978, Vol. 49, No. 5, pp. 472-488.

Shirley, Robert C. and Kent Caruthers. "Strategic Planning for Higher Education." A presentation of Annual Meeting of American Association of State Colleges and Universities. San Antonio, Texas, November 20, 1979. 


\section{Table 1}

\section{An Outline for an Educational Plan}

(University, College, Department, Office)

Carol A. Paul

(10/7/82)

I. History

The history of the unit helps to define what the unit is like and how it became what it is.

II. Mission

Examining and redesigning the mission identifies the general direction of the unit.

III. Enrollment Projections and Nature of the Potential Student Population

Educational plans should be developed on the basis of sound enrollment projections and the nature of the enrollment pool. Such an approach establishes quantifiable numbers while identifying which students are available for recruitment. This permits the matching of students and institutions according to student needs and institutional programs and services.

IV. Major External and Internal Issues/ Constraints Now and in the Near Future (3-5 Years)

Identifying these external and internal issues/constraints defines the possible set of variables that will influence institutional maintenance and growth. Examples of external issues/constraints are the declining numbers of the 18-21 year-old student cohort; the graying of America; the decline of basic skills; the effect of inflation; the nature of the unit's geographic location; the increase in part-time, non-traditional students; the demands of technology; the employment opportunities in service fields, etc. Examples of internal issues/constraints are the tenured nature of faculty; the budgetary cutbacks; the need to increase class size; the changing nature of the new student body; the lack of basic skills; the retentionattrition problem; the resistance to change, etc. To start, these 
issues/constraints should be "laundry lists"; however, their usefulness is dependent upon the ability of the unit to delineate those internal and external issues/constraints that are most important for it to address within the time line of its plan, namely, to identify its priority issues.

V. Assumptions of the Near Future (3-5 Years)

From the information obtained on enrollment projections, the nature of the potential student population and the internal and external issues/constraints, a set of assumptions about the future can be defined.

The first assumption should identify the unit's position on enrollment. The enrollment projections from item III represent baseline projections that assume no programmatic changes. However, the unit should consider the potential student population and assume an ability to recruit and enroll a new type of student which concurrently would increase enrollments beyond the baseline, while requiring new programmatic direction. Finally, the issues/constraints identify the immediate priority issues of the plan. For example, more students with basic skills problems might be recruited which would mandate excellent basic skills programs. Since the future promises a greater number of students with basic skills problems, recruitment and enrollment of these students offers an opportunity to exceed the baseline projections.

VI. Goals and Objectives: Enrollment and Educational Programs

Well stated goals state a specific direction, while specific objectives offer short-term targets that should accomplish the more general goal. Specific objectives should answer who is responsible, what is to be done, and when it should be done. If the assumptions are clearly defined, writing goals/objectives should be a straightforward procedure.

Educational planning merges enrollments with educational programs so goals/objectives are required for these two major areas. If, for example, an educational unit decides not to accept the baseline projections, then goals/objectives need to be set to identify what programs should produce a higher level. 
An example of a goal would be to improve retention. Then, the supporting objective would be: By September 1982, the Dean and the faculty will design and implement a retention program that will increase retention by $5 \%$ each successive year: 1982, 1983, 1984, etc.

VII. Actions/Activities to Achieve Goals/Objectives

Usually actions/activities follow naturally, especially if goals/objectives are specific. Very often the most complex component of action/activities is staffing. That in itself may require a goal/objective for retraining staff or reallocating resources.

VIII. Resources Required

Ideally resources include funding, staffing, facilities, etc. At this juncture, planning is tied to budgeting. Clearly, to be useful, planning must direct budgeting, not vice versa.

IX. Evaluation of Goal/Objectives

Again, if the goals/objectives are specific, the evaluation of criteria can be set directly from these. For example, the evaluation of the objective in item VI involves quantifying the increase in retention each year. Qualitative evaluation might involve ascertaining that the increase is due to the quality and the action of the retention program. 